ESCRITAS Vol. 10 n. 1 (2018) ISSN 2238-7188 p. 231-246

\title{
A TÉCNICA DE GRUPOS FOCAIS NO ENSINO DE HISTÓRIA: UMA NOVA PERSPECTIVA METODOLÓGICA.
}

\section{THE TECHNIQUE OF FOCUS GROUPS IN TEACHING HISTORY: A NEW METHODOLOGICAL PERSPECTIVE.}

\author{
Arnaldo Martin Szlachta Junior ${ }^{1}$
}

\begin{abstract}
Resumo
O campo de ensino de história requer método, pesquisa e análise próprios, e nos últimos anos há diversos trabalhos que debatem sobre os procedimentos no ensino de historia. Nesse artigo abordamos o quanto a pesquisa do ensino de história possuí suas dificuldades desde os processo de formação do professor, as realidades de uma espaço múltiplo e dinâmico em contraste com práticas arcaicas e pouco interessantes, buscamos apresentar a proposta de trabalho de grupos focais dentro do ambiente escolar, associamos essa maneira de análise levando em conta as ações do conceito de aula oficina da educação histórica.
\end{abstract}

Palavras chave: Ensino de História, Grupos Focais, cotidiano escolar, Educação Histórica.

\begin{abstract}
The history teaching field requires method, research and analysis themselves, and in recent years there are several papers that discuss the procedures in history teaching. In this article we discuss how the research history of teaching possess their difficulties from the teacher training process, the realities of a multiple and dynamic space in contrast to archaic practices and uninteresting, we seek to present the proposed work focus groups within the school environment, we associate this way of analysis taking into account the actions of the concept of class workshop of historical education
\end{abstract}

Keywords: History teaching, focus groups, school routine, History Education .

O fazer dos historiadores é característico pela necessidade de desconstruir e reconstruir o passado, por mais presente, ou próximo que este esteja. Como na maioria das vezes não vivenciamos o processo histórico estudado, nossa tarefa é

\footnotetext{
${ }^{1}$ Mestre em História pela Universidade Estadual de Maringá. prof.arnaldo@yahoo.com.br
} 
procurar por fragmentos, vestígios, e, por meio destes, elaborar relatos possíveis. Ao escolhermos determinado objeto de pesquisa, consequentemente, consideramos uma teoria, que fornece bases para se pensar em métodos de acordo com os quais nos movimentaremos em meio às fontes. Por isso, aqui pretendemos trabalhar as questões relativas à natureza da história em diálogo com o olhar lançado aos objetos, métodos e fontes.

O campo do Ensino de História possuí suas características metodológicas principalmente por ter como uma dos seus focos análises que pertencem á práxis escolas e pedagógica. Na academia há uma enorme valorização para pesquisas que primam pro análises quantitativas, e por mais que nos últimos anos houve uma vasta produção de bases qualitativas há aqueles que ainda desclassificam tais pesquisas, ignorando suas contribuições pelo método escolhido.

\section{Grupos focais, promessas e cuidados.}

A prática de pesquisa de grupos focais não é recente nas ciências em geral, há uma vastidão de pesquisas desde os anos 1960 que já tratam das técnicas de grupos focais, principalmente em pesquisas na psicologia e na área da saúde. Nosso objetivo nesse texto é trazer possibilidades de pesquisa para o campo de ensino de história, á partir das metodologias de grupos focais, seus conceitos, finalidades e procedimentos. Tentaremos ainda trazer uma problematização na operacionalização prática e na pesquisa.

Ao fazermos uma análise da literatura sobre os Grupos Focais, na qual não pretendemos ser exaustivos, consideramos três critérios principais: I) Livros especializados em metodologia qualitativa que apresentam de modo destacado a técnica de grupo focal; II) trabalhos alocados na base científica da SciELO à partir dos termos de busca grupo(s) focal(is); III) autores/trabalhos citados pela maioria dos autores consultados nas duas categorias citadas que são tidos como referencias no assunto como: Fiske e Kendall (1990) e Morgan (1992, 1997, 1998).

Vale salientar que por se tratar de uma apropriação metodológica, perspectivas de análise clinicas, desenvolvimentos de conflitos pós resultados e outras abordagens que são específicas da área da saúde não serão apresentadas como possibilidade de trabalho pelo fato de não dialogarem com o nosso campo. 
Nas duas últimas décadas houve um imenso e exaustivo trabalho do uso dos grupos focais em pesquisas cujo objeto eram os programas de Saúde da Família, percebemos em nossa análise de dados que a maior parte dessa produção acadêmica encontrava-se na região Nordeste, principalmente nos estados da Bahia, Ceará e Sergipe (TRAD, 2002). Tais pesquisas são ricas pois reformulam suas perspectivas ao saírem dos espaços instrucionais dos hospitais e dos centros de pesquisas, se distanciando do aspecto técnico e ganhando uma característica mais centrada na humanização (TRAD, 2006).

O grupo focal é uma técnica de pesquisa que permite ao pesquisador obter dados de natureza qualitativa por meio de sessões grupais composta de 6 a 15 pessoas que compartilham algo em comum, por exemplo, sexo, idade ou uma ocupação. Eles refletem um recorte de uma realidade que visa discutir vários aspectos de um determinado tema. Os dados obtidos por essa metodologia possibilitaram o conhecimento de percepções, conceitos, opiniões, expectativas, representações sociais, que venham a ser estudados.

\begin{abstract}
Ao optar por abordar a técnica de Grupos Focais na pesquisa social, é preciso enfatizar que esse debate recebe destaque, nesse momento introdutório, por sua importância para o futuro da pesquisa social, que demanda, cada vez mais, uma postura crítica e dialética, visando à superação dos pontos contraditórios, tornando-os públicos para que possam também ser submetidos a outras críticas. Desta maneira, elegemos a técnica de grupos focais, considerando que seu prestígio e utilização têm crescido bastante no âmbito da pesquisa social, o que requer esforços analíticos que a (re)interpretem e trabalhem em consonância com as demandas dos cidadãos, colocando-a em posição de destaque no campo metodológico. (CRUZ NETO, 2002 p.2)
\end{abstract}

A utilização dos grupos focais data do fim da Segunda Guerra Mundial, quando Bogardus, citado por Morgan ${ }^{2}$, analisou por meio da ótica das ciências sociais os efeitos da propaganda durante a segunda guerra mundial. Apesar do uso dessa metodologia em outras obras, pouco se discutiu e se debateu sobre o tema nos anos seguintes.

Nas últimas três décadas, o uso desse tipo de análise vem sendo mais frequente em trabalhos acadêmicos nos campos da psicologia social, enfermagem e medicina. Houve iniciativas dos professores da Faculdade de Saúde Pública/USP, no

\footnotetext{
${ }^{2}$ Ver: Morgan DL. Focus groups as qualitative research.Newbury Park, CA: Sage Publications; 1988.
} 
estado de São Paulo, entre 1989 e 1992, com grupos que debatiam as instituições de saúde. As experiências descritas demonstraram que a técnica é eficiente, possibilitando, em um período curto de tempo, identificar uma análise aprofundada de problemas a partir do ponto de vista dos entrevistados. (WESTPHAL, 1996 p. 472)

Durante o mesmo período, a pesquisa qualitativa no campo das ciências sociais aplicadas restringiu-se à utilização da observação do participante e de entrevistas direcionadas e únicas. Mais recentemente, os cientistas sociais, inclusive os que dialogam com saúde, educação em saúde, e psicologia voltaram a utilizar entrevistas em grupo, justificando a escolha desse método qualitativo por motivos da convivência que o pesquisador tem com seu objeto, e assim é capaz de conhecer mais aprofundamento aquele número de pessoas e como se constroem as dinâmicas sobre determinados assuntos.

\begin{abstract}
A principal característica da técnica de Grupos Focais reside no fato de ela trabalhar com a reflexão expressa através da "fala" dos participantes, permitindo que eles apresentem, simultaneamente, seus conceitos, impressões e concepções sobre determinado tema. Em decorrência, as informações produzidas ou aprofundadas são de cunho essencialmente qualitativo. [...] Exatamente por isso, as questões aventadas pelo Pesquisador devem ser capazes de instaurar e alimentar o debate entre os participantes, sem que isso equivalha à preocupação com a formação de consensos. Logicamente, algumas opiniões causam mais impacto e polêmica que outras, gerando reações que ora convergem ora divergem. $\mathrm{O}$ importante é que todos tenham possibilidades equânimes de apresentar suas concepções e que elas sejam discutidas e refinadas. (CRUZ NETO, 2002, p. 5)
\end{abstract}

Os grupos focais são utilizados para agrupar percepções, insights e interações que dificilmente seriam obtidas fora do grupo. Os dados obtidos são considerados como o processo do grupo, sendo um conceito distinto em comparação as análises individuais, na qual o pesquisador obtém percepções isoladas (KIND, 2004). Esse método de análise possibilita uma reflexão sobre a soma dos pontos de vista e sentimentos tomados durante a ação, formando uma percepção daquele grupo que converge às várias posições distintas numa linha de raciocínio único, ou seja, seria uma pesquisa qualitativa observando as dinâmicas que permeiam uma sala de aula. (GONDIM, 2004)

A prática de grupos focais, de forma isolada, e associada com a pesquisa do ensino de história através da coleta de dados primários, mostra-se muito útil ao se tratar de uma pesquisa avaliativa, possibilitando uma atenção maior aquela grupo 
específico, dissociada a amostragem social lhe permite compreender inter-relações que não seriam possíveis de percepção inseridas em seu todo (NOVAES, 2000). Tal abordagem, já no processo de uma sequência de encontros os diálogos se estabelecem e é possível constituir uma relação que permita mais sucesso na análises dos dados coletados percebendo as diferentes visões dos sujeitos, contextos sociais e as práticas e propostas que assimilam ou negam (TANAKA; MELO, 2004)

O grupo focal é um método que permite ao pesquisador observar a pluralidade de sujeitos simultaneamente, observando as características de interação grupal como a aceitação ou negação, mesmo que sejam manifestações sutis. Os grupos focais funcionam como um convite a uma apropriação crítica ao pesquisador que queira utilizar essa metodologia no processo de construção do conhecimento. Numa análise desse tipo, o pesquisador obtém uma variedade de informações, sentimentos, experiências, representações de pequenos grupos acerca de um determinado tema. (KIND, 2004)

A utilização de sessões de grupo como técnica de pesquisa é recomendada pela maior possibilidade que oferece para se pensar coletivamente urna temática que faz parte da vida das pessoas reunidas. Pressupondo que percepções, atitudes, opiniões e representações são socialmente construídas, a expressão das mesmas seria mais facilmente captada durante um processo de interação em que os comentários de uns podem fazer emergir a opinião de outros, e em ambientes permissivos pode facilitar a expressão de emoções. Assim, os pesquisadores podem observar como a controvérsia vem à tona e como os problemas são resolvidos. (WESTPHAL, 1996 p.473)

A técnica de grupos focais se fundamenta na tradição do trabalho em grupo executado pelas áreas da saúde como a enfermagem e a psicologia social, já mencionadas.

Dessa forma, encontramos diferentes embasamentos teóricos que adéquam essa metodologia a suas análises no processo de investigação. Em nossa pesquisa, utilizamos a percepção que um grupo focal fosse formado de acordo com o interesse dos estudantes. No colégio foram feitas as propostas, para as duas séries que analisaremos, sobre o interesse em participarem das sessões de grupos de focais sem oferecer nada em troca, nossa intenção era selecionar um número suficiente de alunos que se demonstravam dispostos a colaborar com os debates sem promessas como nota de participação no boletim bimestral, dessa forma conduzimos a pesquisa para uma análise qualitativa buscando baixos níveis de desvios. 
O número de participantes de um grupo focal é condicionado por dois fatores: deverá ser pequeno o suficiente para que todos tenham a oportunidade de expor suas idéias e grande o bastante para que os participantes possam vir a fornecer consistente diversidade de opiniões. Quantificando esse raciocínio, podemos concluir que uma sessão de grupo focal deve ser composta por no mínimo quatro e no máximo doze pessoas (KRUEGER, 1996 Apud CRUZ NETO).

Para chegar aos debates e aos diálogos sobre um assunto previamente determinado, deve-se dar ao grupo uma tarefa específica a ser mediada pelo pesquisador. É necessário que ele permaneça atento para não conduzir o debate de forma a retirar a liberdade do grupo nas discussões apresentando posicionamentos tendenciosos, e não permitir, também, que o assunto entre em caminhos fora do contexto da pesquisa.

Dessa forma, concordamos com Kind que aponta: "o papel do moderador está comprometido também com as premissas desse referencial. Em linhas gerais, se o moderador traz como suporte teórico modelos mais clínicos de condução e análise de grupos, há uma tendência em ser diretivo apenas o mínimo necessário para que não se desvie em demasia do tema da discussão.” (Kind, 2004 p. 130)

A técnica de entrevista em grupo focal mostrou-se muito adequada para a nossas propostas de pesquisa, uma vez que promove discussões sobre o assunto de maneira que se tenha a possibilidade de aproveitar ao máximo as situações e ocasiões graças aos recursos tecnológicos atuais que nos permitem gravar, fotografar e filmar os encontros, dando uma maior liberdade ao pesquisador para a condução de questionamentos aos entrevistados. Nosso propósito diz respeito ao incremento qualitativo da uma investigação social sobre o pensamento do aluno e suas constituições no ensino de história.

Para todo o processo é importante ter os feedbacks, que seriam a respostas dos participantes do processo com o mediador, assim além do mediador ter consciência das questões e problemáticas surgidas do grupos é também uma estratégia para superar limites, na qual se destaque na maioria das vezes um esforço de contextualização cultural, um construção de identidade do grupo. (GATTINARA et al., 1995; TRAD et al, 2002).

Morgan (MORGAN, 1992) aponta que a prática de pesquisa em grupos focais, de acordo com uma análise qualitativa, é mais eficiente e produtiva comparada com a prática de uma observação distante, numa espécie de onisciência científica, na 
qual o pesquisador crê que sua observação não irá interferir em seu objeto, entretanto quando o pesquisador é alheio ao meio jamais haverá uma análise dita de uma imparcialidade da prática do pesquisador. Em relação ao ensino de história é necessário destacar que a figura do professor/pesquisador é muito importante. Quando a coleta de dados e ação da pesquisa é feita pelo docente da turma a empatia permite resultados melhores e mais contundentes.

Gaskell (GASKELL, 2002), entende que para o mesmo número de avaliados o grupo focal é exponencialmente mais eficaz e aponta que a prática fornece critérios sobre o consenso emergente e como as pessoas lidam com problemas e divergências internas; o pesquisado possuí muito mais empatia com os membros podendo expor as questões com mais estímulos, tendo mais liberdade inclusive de tratar com aspectos pejorativos que em muitas vezes são necessários em pesquisas; e por fim há uma construção de experiências, de trocas de preocupações comuns que raramente são notados pelos métodos quantitativos que primam pela repetição de uma ação do que ao aprofundamento de questões ocultas, mas que estão presentes e vivas no coletivo.

Refletindo um pouco mais sobre a dinâmica própria de uma discussão em grupo, que tanto pode servir para identificar o que a distingue do enquadre da entrevista individual, como pode lançar questões sobre a questão do risco de imposição da opinião de uns sobre outros. Para Schrader (SCHRADER, 1987) o autor reconhece, primeiramente, que grupos sociais atingidos coletivamente por fatos ou situações específicas desenvolvem opiniões informais abrangentes sobre estes; deste modo, quando se apresenta uma situação de interlocução entre membros de um desses grupos a respeito de um dado fato ou situação, tais opiniões se impõem, influindo normativamente na consciência e no comportamento individual (SCHRADER, 1987). As pessoas em geral precisam ouvir as opiniões dos outros antes de formar as suas próprias. E constantemente mudam de posição (ou fundamentam melhor sua posição inicial) quando expostas a discussões de grupo.

Morgan (MORGAN, 1998) chama a atenção e apresenta os ditos "mitos" dos grupos focais. Para ele, essa metodologia pode tornar a pesquisa mais cara, quando comparados a métodos como a observação participante, e menos demorados, se comparados, por exemplo, com a entrevista individual. É preciso advertir também que temas de natureza muito pessoal e delicada possivelmente apresentarão resultados decepcionantes se abordados em grupo focal, é precisa ter em mente que não se trata 
de uma ação individualizada (isso pertence a área da psicologia clinica), trata-se de uma análise coletiva cuja amostragem é menor para efeitos qualitativos.

Os grupos focais não podem ser uma prática cotidiana de uma grupo, é preciso ter em mente que estudos com grupo focal não oferecem boas estimativas de frequência, uma vez que não é esse seu propósito (CARLINI-COLTRINI 1996). Outra questão é a dificuldade de garantir um total anonimato; a grande interferência em relação aos juízos de valores do moderador caso não haja o distanciamento necessário; o risco de que as discussões sejam desviadas ou dominadas por poucas pessoas - é importante que o moderador perceba as ações de liderança, mas que não permita a condução dos trabalhos por um único líder - tais aspectos reforçam tanto a importância de levar a cabo uma seleção criteriosa dos participantes, como o fato de que os comentários devem ser interpretados sempre no contexto do grupo e direcionados ao objeto de pesquisa, no caso questões relacionadas com o ensino de história.

Após as discussões apresentadas aqui, tanto no que diz respeito a formação do professor de história, seu ambiente de trabalho e que ele deve ensinar com o currículos, fica em aberto uma questão: qual a postura ou o papel que professor de história deve tomar? Que ações devem acontecer?

\section{Dialogo com metodologia dos grupos focais e a didática da história}

A ideia de didática vem sendo construída e reconstruída ao longo dos anos e, atualmente, com as possibilidades de reprodução que a era digital nos proporciona, o assunto ganha força principalmente como um recurso que permitiria a construção de conhecimentos e significados e não simplesmente como uma mera ilustração dos conteúdos dispostos no livro didático - as novas abordagens caminham para a problematização e enfoques de análises em sala de aula na perspectiva da construção de conhecimento. (BERGMANN, 1990)

Selva Guimarães Fonseca considera que os professores possuem ferramentas teóricas e intelectuais que possibilitam o desenvolvimento da ação mediadora em sala de aula. Foi pensando nesta abordagem que elaboramos essa metodologia de pesquisa, buscando fugir do convencional e propondo uma ação que levasse em consideração a realidade da sala de aula, valorizando as capacidades intelectuais dos alunos e professores, na concepção de criação de narrativas históricas no ambiente escolar. 
[...] professores e alunos não são meros consumidores de materiais, executores de programas de ensino, mas criadores, produtores de saberes. O professor é um profissional que domina não apenas os métodos da construção do conhecimento, mas um conjunto de saberes que possibilita sua socialização e sua reconstrução no processo de ensino e aprendizagem. (FONSECA, 2003, p. 102)

No cotidiano escolar muitas são as ideias e tentativas para um bom trabalho de sala de aula, um trabalho que tenha uma proximidade à realidade do aluno e esteja em sintonia com os debates presentes na academia. Desde muito tempo há estudos sobre a utilização das imagens na composição da história, assim como o seu uso em sala de aula. No ambiente escolar, a presença das imagens, sejam elas desenhos de uma época, pintura ou fotografia, fornece aos professores uma presença significativa no processo de aprendizagem dos alunos da educação básica

A prática cotidiana do ensino de história na educação básica não é uma tarefa fácil, não imaginamos, quando ainda na graduação, que enfrentaremos como professores questões que não circundam os programas das disciplinas cursadas. Essas questões estão tanto na esfera da disciplina do ensino de história quanto na própria realidade de ser professor e ter de aprender a lidar com a indisciplina dos alunos, as questões burocráticas das instituições de ensino e o funcionamento desse todo que forma o sistema educacional do nosso país. Entretanto, se fôssemos adentrar nesses pontos, sem um aprofundamento necessário não conseguiríamos problematizar todas essas relações do professor com o meio seria muito difícil, inclusive, encontrar alguns caminhos.

\section{Alunos múltiplos, currículo e ação dos mediadores culturais.}

Os alunos possuem múltiplas formações culturais, os entendimentos das famílias sobre determinados assuntos se alteram de acordo com os temas que serão abordados. Com todo esse campo de múltiplas possibilidades o professor tem em mãos uma ferramenta fantástica que pode transformar suas aulas que é aproximação junto ao aluno, fazendo-o de mero expectador a agente ativo do processo educacional. Mesmo que atualmente os cursos de formação possibilitam uma carga horária maior ao ensino de história, após reformas nas grades curriculares nos anos 2000.

Apesar de todo esse debate sobre a complexidade da formação do professor de história nas universidades, há a realidade que o recém graduado enfrenta para entender o processo dinâmico de uma escola. Uma série de iniciativas é tomada pelos 
professores que buscam fazer com que os alunos tenham uma relação de significado e significância no aprendizado em história.

Essas ações muitas vezes não estão presentes nos registros de classe, tampouco nos planejamentos e planos de aula que o docente deve entregar no início do período letivo. Isso é péssimo para o campo da pesquisa, já que uma série de ações é omitida pelos professores que se sentem intimidados pela burocracia ou rigidez de determinados programas e currículos que poderiam estar de acordo com a realidade cotidiana do professor em sala de aula.

Mas a atuação de uma ação docente mais próxima e interlocutora ao educando não é simples como apresentada, uma visão como essa tende a positividade e de certa forma a idealização da profissão que conta com grandes dificuldades, merecendo destaque os baixos salários e a indisciplina escolar, somado a isso o professor tem de seguir um planejamento de conteúdos que estejam de acordo com os parâmetros curriculares.

Com tantas dificuldades, alguns professores tendem a questionar esses programas ou parâmetros pré-estabelecidos, como se essa programação deixasse o professor moldado a um sistema inerte e imutável da graduação até o cotidiano escolar. Sacristan, em um dos seus trabalhos intitulado "Compreender e transformar o ensino", apresenta-nos algumas possibilidades da ação do docente em relação às especificações compostas pelos currículos. Observamos o que ele atenta em relação à gestão do professor frente ao currículo:

Transformar em tema central na didática os conteúdos, junto com os temas que geralmente costumam ser vistos como propriamente didáticos ou metodológicos, implica lutar por uma visão mais ajustadas à realidade, mais integradora, oferecer perspectivas mais completas para os professores/as, ampliar o sentido restrito a técnica. (SACRISTAN, 2000, p.122)

$\mathrm{Na}$ formulação do currículo deve se levar em conta sua execução em sala de aula que é um processo dinâmico, pois se estabelece caminhos muito fixos deixará o professor sobrecarregado, sem uma ação transformadora. Entretanto, o agente mais dinâmico desse processo é o professor, que tem a possibilidade de re-selecionar os conteúdos de uma forma que julgue ser mais importante para a formação daquele aluno, por mais que os programas, sejam eles no campo nacional ou regional, busquem uma unificação na execução do trabalho em sala de aula, o que contará mesmo é "final da ponta dessa corda" que é ação do professor que terá como 
resultado seus próprios recortes e destacando aquilo que segundo sua formação e/ou experiência lhe indique como um caminho correto.

Considerar que o ensino se reduz ao que os programas oficiais ou os próprios professores/as dizem que querem transmitir é uma ingenuidade. Uma coisa é o que dizem os professores/as o que devem ensinar, outra é o que eles acham ou dizem que ensinam de outra forma diferente é o que os alunos/as aprendem. (SACRISTAN, 2000, p.131)

Sacristan aborda de uma forma expressiva as vozes que formam esse ensino, que existem maneiras de dizer sobre os conteúdos e de como ele chega até o aluno, o que cada agente desse processo afirma e defende e o que acaba acontecendo no sentido prático tanto sobre a composição do currículo como a assimilação por parte dos alunos.

Um item claro, que inclusive acontece com boa parte dos alunos, é a busca de uma linha teórica ou ideologia de seu professor, modulando, dessa forma, seu discurso nas atividades e avaliações de uma forma que lhe garanta uma melhor visão do professor sobre seu trabalho. Muitas vezes o que nossos alunos escrevem e defendem é apenas feito para a pessoa do professor, não havendo uma problematização ou reflexão realizada propriamente pelo educando.

Nessa mesma linha recorremos a Tomaz T. da Silva que faz considerações sobre o currículo e as ações dos docentes sobre ele. Silva considera que o caminho que percorre o ensino é composto pela linguagem e o processo de transformar o que está escrito numa aula, ou seja, a ação docente ganha muitas possibilidades por meio da função linguística, uma ação pode se transformar, ou até mesmo ganhar significados distintos daquilo que antes se havia sido pensado.

\footnotetext{
A produtividade das práticas de significação é função, entre outras coisas, do caráter indeterminado, aberto, incerto, incontido da atividade lingüística, da atividade de produção de sentido. Se o processo de significação girasse sempre em torno dos mesmos significados e se os significados fossem fixos, se as marcas lingüísticas que utilizamos estivessem vinculadas a significantes, apontariam para significados unívocos, certos, singulares. (SILVA, 2001, p.20)
}

A essa ideia é atribuído o conceito de currículo oculto, ou seja, mesmo tendo um significado, uma estruturação na composição do currículo, o professor no agir da sala de aula consegue mudar a sua aula, e, se quiser, é possível inclusive modificar por completo o que esteja definido na escrita sem alterar ou acrescentar nada. Isso é 
possível, segundo Silva, por meio da variação linguística, que transmite o saber presente no currículo que está estático, frio podendo gerar outras interpretações.

Sobre o que seria um currículo e sua função podemos citar o trabalho que discute a relação do currículo com a história e a teoria, trata-se de um texto de Ivor F. Goodson intitulado "Currículo: Teoria e História", e sobre a função do currículo o autor pondera:

O currículo escrito não passa de um testemunho visível, público e sujeito a mudanças, uma lógica que se escolhe para mediante sua retórica, legitimar uma escolarização [...] enquanto o currículo escrito estabelece a lógica e a retórica da matéria, o que aparece é apenas o aspecto mais tangível, abrangendo padronização de recursos. (GOODSON, 1995, p.21)

Goodson, que é traduzido por Tomaz Tadeu da Silva, reflete que a ação do docente não está intrinsecamente ligada ao currículo, aliás, observa o currículo como um agente burocrático de certa forma, pois trata o currículo escrito como um simples documento de padronização de recursos.

Após as discussões apresentadas aqui, tanto no que diz respeito a formação do professor de história, seu ambiente de trabalho e que ele deve ensinar com o currículos, fica em aberto uma questão: qual a postura ou o papel que professor de história deve tomar? Que ações devem acontecer?

Para responder a isso vamos nos valer de Lana Mara de Castro Siman, que enxerga o professor como um mediador, ou seja, uma pessoa responsável em trabalhar os assuntos relativos a disciplina de história de uma forma que seja possível aproveitar esse conhecimento que o aluno possui previamente para assim poder construir seu entendimento sobre as relações do passado.

\footnotetext{
Para que o ensino de História, todavia, seja levado a bom termo, ao longo de todo o ensino fundamental, torna-se necessário que o professor inclua, como parte construtiva do processo ensino aprendizagem, a presença de outros mediadores culturais, como objetos da cultura, material, visual ou simbólica, que ancorados nos procedimentos de produção do conhecimento histórico possibilitarão a construção do conhecimento pelos alunos, tornando possível "imaginar", reconstruir o não vivido diretamente, por meio de variadas fontes documentais. (SIMAN, 2004, p.88)
}

Esse conceito de imaginar apresentado pela autora talvez seja o laboratório de atuação máxima desse historiador dentro da sala de aula, poder estabelecer uma relação com o presente, com o contato cultural do aluno fazendo com que esse aluno 
tenha condições de criar formas de entendimento sobre uma determinada época, sobre como estabelecer esses diálogos com o passado e como não cometer julgamentos que tendem ao anacronismo. A mediação cultural perpassa o que qualquer atitude de um manual que tente cristalizar um conteúdo e o currículo ganha vida, pois essa mediação trata de uma relação de troca entre a figura do docente e do aluno.

Atualmente, o que o recém-graduado em história acaba encontrando como realidade profissional é um ambiente escolar formado na grande maioria por uma sala, lousa de giz para anotações à frente, com os lugares dos alunos posicionados e organizados um atrás do outro. Esse ambiente, apesar de comum aos olhos dessa atual sociedade, é uma herança de uma tradição escolar com raízes medievais e composição moderna que se manteve até os dias de hoje.

Depois de nos focar no espaço físico que corresponde à escola, e antes de entrar em outras discussões, vamos voltar nossos olhos àqueles que são os sujeitos principais do processo educacional: os alunos. Na grande maioria das vezes pensamos nos jovens do ensino regular os quais a maior porcentagem diz que não gostam ou até mesmo odeiam ter que aprender história. Aqueles que se julgam incapazes de "decorar" o conteúdo acabam inventando as mais criativas formas de "cola", a fim de conseguirem aprovações nas provas e, assim, da forma mais rápida possível, jogarem seus cadernos de anotações e fazer questão de esquecer toda essa "chatice" o mais rápido possível. Talvez essas linhas que você acabou de ler possam lhe soar como mais um desabafo de um profissional da educação, mas essas seriam atitudes inerentes à condição ou natureza do aluno? Ou seria somente um fenômeno ligado a prática do ensino de História?

Tais questionamentos não são respondidos de uma forma precisa e focada, nem será simples encontrar uma fórmula que motive o aluno a aprender história já que o jovem em idade escolar vive a pós-modernidade ${ }^{3}$ enquanto a nossa estrutura educacional, da formação dos professores na universidade, o currículo e até mesmo a estrutura física da escola são instituições modernas.

Os conceitos de Siman vão de encontro com a proposta de Aula Oficina colocada por Isabel Barca, nesse conceito a aula passa ser um momento dinâmico entre alunos e professores, a aula deixa de ser um produto, pronto e acabado passível

\footnotetext{
${ }^{3}$ Quando usamos o termo pós-modernidade estamos usando os conceitos propostos por Zigmunt Bauman, principalmente as obra "A sociedade Individualizada (2008)" e "A sociedade Líquida".(2001)
} 
de total reprodução, Barca considera que o pesquisador deve sabe extrair ao máximo essa multiplicidade dos alunos e convergir isso para a produção de um saber escolar, no caso da história de uma narrativa histórica escolar (BARCA, 2004).

Dessa forma é necessário que o professor consiga mediar as ações para que a inciativa não se perca e a aula acabe se transformando numa grande brincadeira e os propósitos fiquem apenas no planejamento. O professor deve se ater a as linhas de estudo do currículo e através das possibilidades fazer um currículo em ação e quem sabe até observar temáticas dos alunos sejam por falas, ações ou silencio, já que o silêncio ou a sutileza de uma expressa, pode dizer muito sobre o que aqueles alunos estão discutindo.

Uma das principais críticas feitas pelos professores da rede pública de ensino é que as pesquisas, na maioria das vezes, apresentam condições difíceis e digo até, que impossíveis em determinadas situações devido a essa formação deficitária dos professores na universidades, a uma escola liga ás raízes modernas e com alunos múltiplos, mas que suas possível contribuições para o debate historiográfico do ensino acabem se perdendo devido a toda uma estrutura arcaica e quase que totalmente desinteressante.

O Aspecto de aula Oficina de Barca é um caminho interessantíssimo para pesquisas nessa área, mas sabemos que não seria possível construir uma pesquisa de qualidade apenas com boas ideias e inciativas, é preciso debater os métodos utilizados no ensino de história. Na minha dissertação de mestrado e em outros trabalhos acadêmicos busquei a constituição dos grupos focais de uma maneira que poderia fazer uma aula/pesquisa dinâmica e eficiente já que é proposto uma visão qualitativa e não quantitativa através dos Grupos focais.

Em alguns trabalhos na sala de aula preferi optar pela técnica dos grupos focais para poder ter uma visão melhor sobre a percepção que os alunos tinham de determinado assunto, geralmente utilizei os finais dos ciclos do ensino fundamental e médio e como eles assimilam o objeto de cada pesquisa.

\section{Referências Bibliográficas}

BARCA, Isabel. Aula oficina: do Projeto à avaliação. Para uma educação de qualidade: Atas da Quarta Jornada de Educação Histórica. Braga, Centro de Investigação em Educação (CIED)/Instituto de Educação e Psicologia, Universidade do Minho, p. 131-144, 2004. 
BAUMAN, Zigmunt. Modernidade líquida. Tradução Plínio Dentzien. Rio de Janeiro: Jorge Zahar Editor, 2001.

Z. A sociedade individualizada. Vidas Contadas e histórias vividas. Tradução José Gradel. Rio de Janeiro: Jorge Zahar, 2008.

BERGMANN, Klaus. A história na reflexão didática. Tradução de Augustin Wernet. Revisão de Marcos A. Silva. In: Revista Brasileira de História, São Paulo, SP, v.9, n.19: 29-42. Set. 1989 / Fev. 1990.

CARLINI-COTRIM, B. Potencialidades da técnica qualitativa grupo focal em investigações sobre abuso de substâncias. Rev. Saúde Pública, São Paulo, v. 30, n. 3, p. 285-93, 1996.

CRUZ NETO, Otávio. Grupos Focais e Pesquisa Social Qualitativa: o debate orientado como técnica de investigação. In: Anais do XIII Encontro da Associação Brasileira de Estudos Populacionais, realizado em. Ouro Preto, Minas Gerais, 2002 pp. 5 - 6.

, O.; MOREIRA, M. R.; SUCENA, L. F. M. Grupos focais e pesquisa social qualitativa: o debate orientado como técnica de investigação. In: ENCONTRO DA ASSOCIAÇÃO BRASILEIRA DE ESTUDOS POPULACIONAIS. 13., ABEP, 2002, Ouro Preto. Disponível em: www.dppg.cefetmg.br/mtp/Tecnicade GruposFocaisdoc. Acesso em: 15 abr. 2008.

FLICK, U. Entrevista episódica. In: GASKEL, G.; BAUER, M. W. (Org.). Pesquisa qualitativa com texto, imagem e som: um manual prático. Petrópolis: Vozes, 2002. p. 114-136.

2004.

U. Uma introdução à pesquisa qualitativa. Porto Alegre: Bookman,

GASKELL, G. Entrevistas individuais e grupais. In: GASKELL, G.; BAUER, M. W. (Org.). Pesquisa qualitativa com texto, imagem e som: um manual prático. Petrópolis: Vozes, 2002. p. 64-89.

G.; BAUER, M. W. (Org.). Pesquisa qualitativa com texto, imagem

e som: um manual prático. Petrópolis: Vozes, 2002.

FONSECA, Selva Guimarães. Didática e Prática de Ensino de História, Campinas, SP. Ed Papirus, 2003.

FORQUIN, J. Escola e cultura: As bases sociais e epistemológicas do conhecimento escolar. Porto Alegre: Artes Médicas, 1993.

GONDIM, Sônia Maria Guedes. Grupos Focais como Técnica de Investigação Qualitativa: Desafios Metodológicos. In: Paidéia, 2003,12(24), p.149-161

S. M. G. Perfil profissional e mercado de trabalho: relação com formação acadêmica pela perspectiva de estudantes universitários in: Estud. Psicologia, Natal, v. 7, n. 2, 2002.

GOODSON, Ivor F. Currículo: teoria e História. Petrópolis: Vozes, 1995 Tradução de Tomaz Tadeu da Silva. 
KIND, Luciana. Notas para o trabalho com a técnica de grupos focais. In: Psicologia em Revista, Belo Horizonte, v. 10, n. 15, p. 124-136, jun. 2004

LIMA, M. T.; BUCHER, J. S. N. F.; LIMA, J. W. O. A hipertensão arterial sob o olhar de uma população carente: estudo exploratório a partir dos conhecimentos, atitudes e práticas. In: Cad. Saúde Pública, Rio de Janeiro, v. 20, n. 4, p. 1.079-87, 2004.

MASSIMI, Marina, As idéias Psicológicas na Produção Cultural da companhia de Jesus no Brasil do século XVI e XVII. In: História da Psicologia no Brasil: novos estudos orgs. Marina Massimi, Maria do Carmo Guedes; revisão André Luís Masiero, São Paulo: EDUC; Cortez, 2004

MORGAN, D. L. The Focus Group Guidebook. Thousand Oaks: Sage, 1998.

Doctor: caregiver relationships: an exploration using focus groups. In: CRABTREE, B. F.; MILLER, W. L. (Ed.). Doing qualitative research. Newburry Park: Sage, 1992.

MORGAN, D. L. Focus group as qualitative research. London: Sage, 1997.

NOVAES, H. M. D. Avaliação de programas, serviços e tecnologias em saúde. In: Revista de Saúde Pública, São Paulo, v. 34, n. 5, p. 547-559, 2000.

NUNES M. O. et al. O agente comunitário de saúde: conquistas e conflitos desse personagem híbrido e polifônico. In: Cad. Saúde Pública, Rio de Janeiro, v. 18, n. 6, p. 1.639-1.646, 2002.

OGIBA, Sonia M. M. A produção do conhecimento didático e o pós-estruturalismo: potencialidades analíticas. In: VEIGA-NETO, A (Org) Crítica pós-estruturalista e educação. Porto Alegre. RS. Sulina, 1995.

PAIN, Antônio Elison. Memórias e experiências do fazer-se professor(a) de História. Capítulo II: Mapeando cânones contemporâneos de formação de professores. (Tese de doutoramento) São Paulo. Campinas. Faculdade de Educação. 2005. p. $99-167$

PIZZOL, S. J. S. Combinação de grupos focais e análise discriminante: um método para tipificação de sistemas de produção agropecuária. In: Rev. Econ. Sociol. Rural, Brasília, v. 42, n. 3, p. 451-468, 2004

RÜSEN, Jörn. Didática da história: passado, presente e perspectivas a partir do caso alemão. Práxis Educativa, Ponta Grossa-PR, v.1, n.1, 15 jul./dez. 2006. Tradução de Marcos Roberto Kusnick.

SACRISTAN, J. G. e GÓMEZ, A. I. P. Compreender e transformar o Ensino. Porto Alegre, Artmed: 2000.

SCHRADER, A. Introdução à pesquisa social empírica. Porto Alegre: Globo, 1987. 
SILVA, Tomaz T. da. O currículo como fetiche. B.H.: Autentica, 2001.

SIMAN, Lana Mara de Castro. O papel dos mediadores culturais e da ação mediadora do professor do conhecimento histórico pelos alunos. In:

THIESSE, Anne-Marie. La création des identités nationales. Europe XVIIe - Xxe siècle. Paris: Éditions Du Seuil, 1999, p. 322.

STEWART, D. W.; SHAMDASANI, P. Focus group research: exploration and discovery. Newburry Park: Sage, 1990

TANAKA, O.; MELO, C. Reflexões sobre a avaliação em serviços de saúde e a adoção das abordagens qualitativa e quantitativa. In: BOSI, M. L. M.; MERCADO, F.

J. (Org.). Pesquisa qualitativa de serviços de saúde. Petrópolis: Vozes, 2004. p. 121-136.

TRAD, L. A. B. Humanização do encontro com o usuário no contexto da atenção básica. In DESLANDES, S. F. (Org.). Humanização dos cuidados em saúde: conceitos, dilemas e práticas. Rio de Janeiro: Fiocruz, 2006.

TRAD, L. A. B. et al. Estudo etnográfico de satisfação de usuário do Programa de Saúde da Família (PSF) na Bahia. In: Ciência \& Saúde Coletiva, Rio de Janeiro, v. 7, n. 3, p. 581-589, 2002.

VEIGA, L.; GONDIM, S. M. G. A utilização de métodos qualitativos na Ciência Política e no Marketing Político. In: Opin. Publica, Campinas, v. 7, n. 1, p. 1-15, 2001.

WELLER, W. Grupos de discussão na pesquisa com adolescentes e jovens: aportes teórico-metodológicos e análise de uma experiência com o método. Educ. Pesqui. São Paulo, v. 32, n. 2, p. 241-260, 2006.

WeStPhal, Márcia Faria. Participação Popular e Políticas Municipais de Saúde: Cotia e Vargem Grande Paulista. Tese Apresentada ao Departamento de Prática de Saúde Pública, da Faculdade de Saúde Pública da USP, para Concurso de Livre Docência. USP. São Paulo. 1992.

, Márcia Faria, e outros. Grupos focais: experiências precursoras em programas educativos em saúde no Brasil, In: Bol Oficina Sanit Panam 120(6), 1996 pp. 472-482.

WESTPHAL, M. F. Uso de métodos qualitativos no estudo de movimentos sociais por saúde. In: SPINOLA, A. W. P. et al. (Org.). Pesquisa social em saúde. São Paulo: Cortez; 1992. p. 117-24.

WORLD HEALTH ORGANIZATION. The focus group manual. Genebra: WHO, 1992. (Methods for Social Research in Tropical Disease, 1). 